do it justice, homeopathy needs a new paradigm. Call me naïve, but I had thought that a new paradigm is needed when the experimental data no longer fit the existing ones. In the case of homeopathy, this is evidently not the case. The results of the Spence study are very easily explicable within the existing paradigm. The bulk of the randomised controlled trials evidence tells us that homeopathic remedies are placebos. ${ }^{2}$ The improvement observed by Spence et $a /$ is therefore probably due to a range of factors unrelated to the treatment itself: natural history of the disease, regression to the mean, social desirability, concomitant interventions, etcetera.

If Swayne suggests that we should take observational studies more seriously than randomised controlled trials, he is not really advocating a paradigm shift. De facto, he is suggesting to implement double standards - one for homeopathy and one for conventional medicine. Or does he propose that we apply his standard throughout medicine? In this case, we have to concede that HRT reduces cardiovascular and cancer risks (as shown by observational studies) and ignore that it does, in fact, achieve the opposite (as demonstrated in randomised controlled trials). The 'paradigm pioneer' is thus disclosed as what he really is: a misguided evangelist preaching a gospel that leads us straight back into the dark ages of medicine, ${ }^{3}$ to the indisputable detriment of our patients.

\section{Edzard Ernst}

Complementary Medicine, 25 Victoria Park Road, Exeter, EX2 4NT.

E-mail: Edzard.Ernst@pms.ac.uk

\section{REFERENCES}

1. Spence DS, Thompson EA, Barron SJ. Homeopathic treatment for chronic disease: a 6-year, universityhospital outpatient observational study. J Altern Complement Med 2005; 11(5): 793-798.

2. Ernst E. A systematic review of systematic reviews of homeopathy. Br J Clin Pharmacol 2002; 54(6): 577-582.

3. Singh S, Ernst E. Trick or treatment? Alternative medicine on trial. London: Transworld Publishers, 2008

DOI: 10.3399/bjgp08X279850

\section{Spinal manipulation}

I am relieved that Ernst does not include spinal manipulation in his grouping of such therapies, as it is well known to be of ancient lineage, having been practiced 'throughout human history'. ${ }^{1}$ It was indeed taught by Hippocrates; little could be more orthodox. Even so, Ernst does write one sentence on the subject. He refers to 'standard care' without defining its scope, and he asserts that spinal manipulation is 'associated with frequent, moderately severe adverse effects and less frequent, serious risks'.2

In our first book, ${ }^{1}$ critically guided by the one-time Director of Neurology of the Royal College of Surgeons, Burn and I included references to 20 -odd papers detailing injury due to manipulation. The majority of these referred to isolated cases, the overall total being very small. In view of the many thousands of spinal manipulations practised every day over much of the world, it is abundantly clear that the incidence of harm is minute. In nearly 40 years using many manipulative techniques I am aware of doing harm on one occasion! Of course there may have been others, but I think I would have noticed if it had been of frequent occurrence, as Ernst suggests.

The scientific bases and the limitations of musculoskeletal medicine are documented in accessible form..$^{3,4}$ It is the awareness of the contraindications to manipulation and their meticulous observance that in fact make it so remarkably safe a therapy.

\section{John K Paterson}

17 Alder Court, Union Lane, Chesterton, Cambridge.

E-mail: j.paterson275@btinternet.com

\section{REFERENCES}

1. Wyke BD. Foreward to Burn, L and Paterson JK. An introduction to medical manipulation. Lancaster: MTP Press, 1985.

2. Ernst E. Complementary and alternative medicine: what the NHS should be funding? Br J Gen Pract 2008; 58(548): 208-209.

3. Burn L, Paterson JK. Musculoskeletal medicine, the spine. London: Kluwer Academic Publishing, 1990.
4. Paterson JK. Musculoskeletal medicine in clinical practice. London: Springer Verlag, 2006.

DOI: $10.3399 /$ bjgp08X279869

\section{Advertisements}

In a week when the government announced its plans for 'well notes' I (and presumably all college members) received a government pamphlet, disguised under the camouflage of 'TSO' (The Stationary Office) purporting to be 'An evidencebased approach for General Practitioners' on 'Advising Patients About Work' enclosed with my College journal.

The publication claims but does not cite evidence of causation for unemployment on medical expense, poor general health, mental health problems, and mortality. I accept evidence of association of unemployment with all these problems but don't expect a supposedly academic College to fund the promulgation of sloppy ideas by a government that appears to be attempting to change NHS general practice into a Nationalised Occupational Medical Service by extending opening hours and devising a 'well note'.

The Editor would have prevented such wild claims being made in the pages of the Journal, rather than simply being included within a postal cover that gave them an improper credibility. The government's view of 'evidence' appears to fall short of any academic definition. It seems that the Editor's authority should be extended beyond the contents of the Journal itself to the envelope in which it comes.

College benefits scarcely extend beyond receiving the Journal and using some letters after my name: I do not pay the best part of $£ 500$ to be lobbied by the English Department of Health! If the College is to act as an agent of state propaganda, College officers should let us know how many pieces of silver are to be exchanged.

\section{Andrew J Ashworth}

Davidson's Mains Medical Centre, 5 Quality Street, Edinburgh, EH4 5BP.

E-mail: aashworth@pearlmedical.co.uk

DOI: 10.3399/bjgp08X279878 